Hickman, R., Ashiru, O., Banister, D.

\title{
TRANSITIONS TO LOW CARBON TRANSPORT FUTURES. STRATEGIC CONVERSATIONS FROM LONDON AND DELHI
}

Dr Robin Hickman,

Associate Director, Transport Research

Halcrow Group Ltd

Vineyard House, Brook Green

Hammersmith, UK, W6 7BY

0044-(0)208-233-3555

Research Fellow

Transport Studies Unit,

Oxford University Centre for the Environment,

University of Oxford, South Parks Road,

Oxford, UK, OX1 3QY

robin.hickman@ouce.ox.ac.uk

\section{Olu Ashiru}

Takedo International and Halcrow Group Ltd

Research Student, Centre for Transport Studies, Imperial College London ashiruo@halcrow.com

\section{Professor David Banister}

Transport Studies Unit,

Oxford University Centre for the Environment,

University of Oxford, South Parks Road,

Oxford, UK, OX1 3QY

david.banister@ouce.ox.ac.uk 


\section{ABSTRACT}

Climate change is a global problem and across the world there are major difficulties being experienced in reducing carbon dioxide $\left(\mathrm{CO}_{2}\right)$ emissions. The transport sector in particular is finding it difficult to reduce $\mathrm{CO}_{2}$ emissions. This paper reports on two studies carried out by the authors in London (UK) and Delhi (India). It considers the common objectives for transport $\mathrm{CO}_{2}$ reduction, but the very different contexts and baselines, potentials for change, and some possible synergies.

Different packages of measures are selected and scenarios developed for each context which are consistent with contraction and convergence objectives. $\mathrm{CO}_{2}$ reduction potentials are modelled and quantified by package and scenario. London is considering deep reductions on current transport $\mathrm{CO}_{2}$ emission levels; Delhi is seeking to break the huge projected rise in transport $\mathrm{CO}_{2}$ emissions.

The scale of policy intervention required to achieve these goals is huge and there is certainly little public discussion of the magnitude of the changes required. The paper argues for a 'strategic conversation' at the city level, using scenario analysis, to discuss the priorities for intervention in delivering low carbon transport futures. A greater focus is required in developing participatory approaches to decision making, alongside network investments, urban planning, low emission vehicles and wider initiatives. Aspirations towards equitable target emissions may assist in setting sufficiently demanding targets. Only then is a wider awareness and ownership of potential carbon efficient transport futures likely to take place. 


\section{TRANSITIONS TO LOW CARBON TRANSPORT FUTURES. STRATEGIC CONVERSATIONS FROM LONDON AND DELHI}

\section{INTRODUCTION}

Cities are experiencing huge change in terms of their development and mobility patterns. The current travel patterns and future business as usual (BAU) projections are clearly unsustainable and the transport sector must contribute much more fully to achieving greenhouse gas (GHG) and carbon dioxide $\left(\mathrm{CO}_{2}\right)$ reduction targets (Hickman and Banister, 2007; Hickman et al., 2009, 2010). There is an opportunity for cities in emerging countries to develop their own strategies and to switch to low carbon systems without passing through the period of oil dependency experienced in the western industrialised nations. The baselines for countries are very different (Table 1), yet there are many transferable lessons to be learned. The sustainable mobility approach requires clear and innovative thinking about city futures in terms of the reality (what is already there), desirability (what we would like to see), and the role that transport can (and should) play in achieving sustainable cities. This balances the requirements along the physical dimensions (urban structure and traffic) against the social dimensions (people and proximity) (Banister, 2008).

\section{TABLE 1}

Population growth, increased urbanisation and globalisation, increased average incomes, aspirations and consumption are all likely to lead to increased travel demand. The supply of transport funding, infrastructure and behavioural change initiatives to meet these challenges lags behind the growth in demand and is not likely to meet the ambitions for $\mathrm{CO}_{2}$ emission reduction. Alternative futures are required to help mitigate and adapt to the impacts of climate change. The real challenge in implementation is that all acceptable futures in environmental (and wider sustainability) terms represent radical changes to the current trends, and they act against current dominant and often ingrained factors. These futures are not easy to deliver, particularly in an era of economic difficulty and likely reduced spending levels in the transport sector (at least for many western industrialised countries). 'Strategic conversations' are urgently needed at the city level to debate the priorities for intervention in delivering lower carbon transport futures.

A number of authors are examining these difficulties concerning the future role of transport in a carbon constrained world (for example, Hughes, 1993; Banister et al., 2000; OECD, 2000; Schipper and Fulton, 2003; Geurs and Van Wee, 2004; Åkerman and Höjer, 2006; Hickman and Banister, 2007; Anable and Bristow, 2007; Chapman, 2007; Bristow et al., 2008; Schäfer et al., 2009; Sperling and Gordon, 2009; Yang et al., 2009; Gilbert and Perl, 2010; Hickman et al., 2010; Brand et al., 2010); others consider transport as part of wider energy reduction futures (Mackay, 2009). All suggest the need for radical trend-breaks in terms of moving towards low carbon transport futures. There is an earlier and extensive, related literature on developing sustainable transport (for example, Thompson, 1977; Pharoah, 1992; Newman and Kenworthy, 1999; Gwilliam, 2002; Banister, 2005; Hickman et al. 2011; and many more). 
Scenario-based methodologies provide a very useful means for analysing uncertain futures, and there is a rich tradition to draw on in terms of approach (Lindblom, 1959; Kahn and Wiener, 1967; Robinson, 1982, 1990; Schwartz, 1996; Dreborg, 1996; Van der Heijden, 1996; Godot, 2000; and Frommelt, 2008). This paper draws on these approaches and develops low $\mathrm{CO} 2$ transport emission pathways at the city level. Two case studies are used - in London and Delhi - representing practice in the western industrialised and emerging Asian countries ${ }^{1}$. The main contributions of the paper are in providing a relative comparison of trajectories between two very different contexts, and in developing a framework, or ambition, for achievement using per capita 'end state' targets. Alongside there should also be further analysis, perhaps on a budgetary (the 'area under the line') and intensity basis (such as $\mathrm{CO}_{2}$ emissions per GDP or other metrics).

\section{A COMMON OBJECTIVE?}

Concerns about the warming of the climate have been expressed for over 30 years. Giddens (2009) describes some of the political history, noting the often abstract and elusive nature of the problem, one that suffers from 'future discounting' (a small reward offered now will normally be taken in preference to a much larger one offered in the future). There are also difficulties for 'orthodox' politics in addressing the topic, and meanwhile potentially devastating impacts ahead. The Intergovernmental Panel on Climate Change (IPCC) ${ }^{2}$ has developed much of the accepted basis for understanding the likely causes, future trajectories and impacts.

Stern (2009) builds on and moves beyond this discourse, developing 'contraction and convergence' principles (drawing from Meyer and GCI, 2000) and a 'blueprint' for change. He makes the link between climate change and poverty, arguing that both issues need to be addressed, hence the strong equity dimension. Stern argues against delaying action and instead that we should invest immediately and substantially in clean technologies and low carbon energy. Holding global concentrations of $\mathrm{CO}_{2}$ to around $500 \mathrm{ppm} \mathrm{CO}_{2} \mathrm{e}$ give a $96 \%$ probability of a temperature rise over $2^{\circ} \mathrm{C}$, a $44 \%$ probability of over $3^{\circ} \mathrm{C}$, and $11 \%$ of over $4^{\circ} \mathrm{C}$ (Table 2). There are advocates for different stabilisation levels, but Stern argues that these are problematic: lower targets being implausible in the short to long term; higher targets associated with unacceptable negative impacts. In relation, the business as usual concentration level is estimated at around $750 \mathrm{ppm} \mathrm{CO}_{2} \mathrm{e}$ and the current (2010) levels are around $435 \mathrm{ppm} \mathrm{CO}_{2} \mathrm{e}$, and rising by 2.5-3.0 ppm per year, hence the 'window of opportunity' is narrowing alarmingly. Stern (p.54) suggests that action within his central case would amount to around $2 \%$ of global GDP per year, or about $\$ 1$ trillion per annum.

TABLE 2

\footnotetext{
${ }^{1}$ This does not suggest that common template strategies can be developed for a number of cities in a particular region. The context for each city is different and unique transport strategies need to be developed. Case study analysis however can provide insights in terms of different baselines and typologies.

2 The IPCC's Fourth Assessment Report (FAR) (2007) concludes that: "Most of the observed increase in global average temperatures since the mid-20th century is very likely [95\% probability] due to the observed increase in anthropogenic greenhouse gas concentrations."
} 
The Stern blueprint is for a peak in emissions within 10 years. This means a global reduction in cross sectoral $\mathrm{CO}_{2}$ emissions of at least 50\% from 1990 levels (from over $50 \mathrm{GtCO}_{2} \mathrm{e}$ now to $20 \mathrm{GtCO}_{2} \mathrm{e}$ ) by 2050 . For developed countries this means an $80 \%$ reduction in $\mathrm{CO}_{2}$ emissions on 1990 levels - to 2 tonnes per capita per annum by 2050 (with the Climate Change Act 2008 this is now a legally binding target for the UK).

If this argument is translated to the transport sector, and it is assumed that the transport sector accounts for $25 \%$ of $\mathrm{CO}_{2}$ emissions, this equates to around 0.5 tonnes per capita within transport ${ }^{3}$. The richer cities (e.g. London) are thus looking at major $\mathrm{CO}_{2}$ emission reductions, in the order of $60-90 \%$ depending on their baseline, with the poorer cities (e.g. Delhi) having a substantial increase (say $+200 \%$ ), all on 1990 figures. This increase in current $\mathrm{CO}_{2}$ emission levels for the emerging countries is consistent with the 'developmental imperative' - the poorer nations have contributed only marginally to historical $\mathrm{CO}_{2}$ emissions and must have the chance to develop even if this raises their emissions in the short term (Giddens, 2009). The key is to avoid and achieve a reduction against the business as usual (BAU) projection which, in Asia for example, represents a very large increase in transport $\mathrm{CO}_{2}$ emissions over time, in per capita and absolute terms. These types of futures are all dramatic 'trend-breaks', but represent the scale of change implied by the strategic $\mathrm{CO}_{2}$ emission targets that are gradually being adopted around the world.

There are important issues to debate within this broad aspiration, whether an equitable target by city or wider jurisdictions is achievable, or indeed necessary, not to mention the costs and wider economic and social equity impacts. There are major allocation issues to think through ${ }^{4}$. However, this approach does provide an initial benchmark for city comparison. A tradable element may provide some flexibility in emission allocation, associated budgets and 'spend'. Targets and budgets may also be conceived on an intensity basis, perhaps against GDP growth or other metrics. Whatever the definition(s), deep aggregate reductions will still need to be made somewhere in the transport sector against a business as usual projection, or elsewhere in other sectors, and to varying degrees depending on spatial level and context. The consequences of not reaching these scales of change are great, as even modest levels of sea level rise are likely to be devastating for a large number of cities; many are located in coastal areas at sea level or where rivers flow into the sea. When sea level rise is combined with river flooding from high intensity rainfall, and with surges, the overall impacts will be augmented and severe (Nicholls et al., 2008).

\footnotetext{
${ }^{3}$ Note that this paper only covers land based emissions, not emissions from international aviation or shipping. There are important wider issues and problems here, for example in the growth of international air travel. However these are not discussed in this paper. See, for example, Bows and Anderson (2007) on possible implications of growth in air travel, and Linnerud and Holden (2011) for increases in leisure travel (international) by those who may reduce everyday travel (local).

${ }^{4}$ For example, the $\mathrm{CO}_{2}$ emissions derived from manufacturing and freight movements in China and associated with consumer good purchasing in the West are currently allocated to China. The $\mathrm{CO}_{2}$ emissions from international air and shipping movements are usually omitted from target discussions and agreements - yet the West is associated with more than their 'fair share' of these.
} 
This paper now examines these broad principles of carbon reduction in transport within the two contrasting cities of London and Delhi. It seeks to explore the different targets, the scenarios, and the means by which different options can be combined in different ways to meet the challenges ahead.

\section{LONDON}

\subsection{Context and Baseline}

London is aiming to become a 'model' sustainable city that can combine population growth with economic prosperity and equity, but at the same time reduce its carbon emissions. Current levels of cross sectoral emissions (2006) in London are around $44 \mathrm{MtCO}_{2}$ (million tonnes of carbon dioxide). London's population is expected to grow by $23 \%$ to 9 million in 2050 from 2006 levels, and the economy will grow by between $100 \%$ and $150 \%$ over the same period (GLA, 2009).

A large amount of strategic forward planning and analysis has been carried out by the public agencies in London. Transport for London has produced Transport 2025 (T2025) (TfL, 2006) and the Mayor's Transport Strategy (TfL, 2009). The Greater London Authority has produced the London Plan (GLA, 2009) and Climate Change Action Plan (CCAP) (GLA, 2007). The headline target adopted for London is a $60 \%$ reduction in $\mathrm{CO}_{2}$ emissions by 2025, across all sectors, on a 1990 base (Climate Change Action Plan, 2007). A legally binding $80 \% \mathrm{CO}_{2}$ emissions reduction target (1990-2050) is now in place for the UK (from 2008) and there are three budget periods (2008-2012, 2013-2017, 2018-2022). At both the UK and London levels there are no sectoral specific targets for transport,

\subsection{Scenario Testing}

The London low carbon scenario analysis draws on work carried out in the VIBAT London study ${ }^{5}$. This examined low carbon transport futures for London to 2025 and 2050 and developed a transport and carbon simulation model (TC-SIM) of the city. Current transport emissions in London are running at just under $10 \mathrm{MtCO}_{2}$, equating to over 1.4 tonnes $\mathrm{CO}_{2}$ per person (2006). A forecast year of 2030 is used in the analysis in this paper, and the BAU projection to 2030 is for a gradual increase in emissions, reflecting an increase in population. The London transport target for 2030, assuming transport contributes its 'fair share' to the cross-sectoral target, is to reach under $4 \mathrm{MtCO}_{2}$.

\footnotetext{
${ }^{5}$ More details of the London context, modelling approach and scenarios can be found in the Stage 1-3 background reports to the VIBAT London project (Hickman et al., 2009; Hickman et al., 2010). For paper brevity they are not included here. Details are also found on www.vibat.org. The modelling approach is described in Ashiru et al. (2009) and uses modelled runs of policy packages using the London Transport Survey (LTS) model, a vehicle fuel penetration spreadsheet developed by Defra and various other databases. The data is combined into a spreadsheet model of London which estimates impacts against different packages and levels of policy application. There are important issues of double counting and potential synergies between packages - these are not modelled within this analysis due to a lack of current evidence; an additivity principle is taken when considering impacts of multiple policy packages at the scenario level (see further discussion in Hickman et al., 2009).
} 
The modelling examines combinations of policy interventions, grouped into policy packages (PPs), which can help reduce transport $\mathrm{CO}_{2}$ emissions. The PPs considered in the London work are:

- PP1: Low Emission Vehicles

- PP2: Alternative Fuels

- PP3: Pricing Regimes

- PP4: Public Transport

- PP5: Walking and Cycling

- PP6: Strategic and Local Urban Planning

- PP7: Information and Communication Technologies (ICT)

- PP8: Smarter Choices 'Behavioural' Measures

- PP9: Ecological Driving and Slower Speeds

- PP10: Long Distance Travel Substitution

- PP11: Freight Transport

A description of Scenarios 1-3 is given below, together with key transport outputs in Figure 1 (aggregate transport $\mathrm{CO}_{2}$ emissions), Figure 2 (mode share by distance) and Figure 3 (per capita transport $\mathrm{CO}_{2}$ emissions).

- Baseline (1990 - 2006)

- Business as Usual (BAU) Scenario (2030): this future is an extension of existing trends over the next 20 years - some investment in public transport, limited change in the efficiency of the car stock and in the use of alternative fuels, but there is no coherent strategy for accelerated change.

- Scenario 1 - Lower Carbon Driving (2030): seeks an approximate 40\% reduction in transport $\mathrm{CO}_{2}$ emissions, on 1990 levels. However, this is reliant on an ambitious implementation of technological measures (low emission motor vehicles and alternative fuels $-95 \mathrm{gCO}_{2} / \mathrm{km}$ ).

- Scenario 2 - More Active Travel (2030): seeks an approx. 40\% reduction in transport $\mathrm{CO}_{2}$ emissions, on 1990 levels. However, it is less optimistic about the potential implementation of low carbon vehicles and relies more on public transport, walking and cycling and smarter choice investment.

- Scenario 3 - Sustainable Transport (2030): combines the best technological and behavioural application of Scenarios 1 and 2 to deliver an approx. $75 \%$ reduction in transport $\mathrm{CO}_{2}$ emissions, on 1990 levels. It is very optimistic about levels of application of policy levers and their effectiveness.

FIGURE 1

FIGURE 2

FIGURE 3

3.3 Optimal Pathways: Scenario 3 - Sustainable Transport 
The most effective scenario (Scenario 3) is described in more detail below. This pushes extremely hard on all of the available policy levers and implements all technological and behavioural options to a high intensity level. It envisages very high levels of walking and cycling, and achieves a 75\% reduction in transport $\mathrm{CO}_{2}$ emissions on 1990 levels. An important feature can be seen in Figure 2 - car distance reduces in Scenario 3 (and 2) - overall distance is held constant, with the difference taken up by a very large increase in walking and cycling. Figure 3 shows that per capita emissions reduce to below 0.5 tonnes per capita under Scenario 3.

- PP1 Low Emission Vehicles: an intensive application of low emission vehicles occurs, similar to Scenario 1. The total car/light goods vehicle (LGV) fleet achieves an average of $95 \mathrm{gCO}_{2} / \mathrm{km}$ and the total heavy goods vehicle (HGV) fleet an average of $900 \mathrm{gCO}_{2} / \mathrm{km}$ (fully loaded) by 2030 . This is a very ambitious level of technology penetration based on current rates of technological penetration, which are relatively slow.

- PP2 Alternative Fuels: a low intensity application of this policy package is applied and viewed as more realistic bearing in mind the recent scepticism concerning the role of biofuels and wider alternative fuels. The assumption is for a low car and bus penetration rate into the vehicle fleet by 2030 (car $0 \%$ alternative fuel - consisting of petrol $80 \%$, diesel $20 \%$; bus $5 \%$ alternative fuel - consisting of diesel 95\%, biofuel 5\%). The RFA (2008) recommends a limit of 5\% renewable transport fuel by volume by 2013, illustrating the potential difficulties in mainstreaming biofuels in transport.

- PP3 Pricing Regimes: congestion charging or area-wide road pricing could potentially make a substantial difference to $\mathrm{CO}_{2}$ emissions on a Londonwide scale. There are political difficulties with implementing this package. This scenario assumes a medium level application of the congestion charge (congestion charging London-wide) and a medium application of parking charging (higher charges and a tighter supply). This gives clear signals to consumers to switch to more efficient cars or to other modes of transport. This is much more progressive than the current London stance, where the congestion zone has been reduced in size (removal of Western Extension in January 2011).

- PP4: Public Transport: public transport investment is critical in allowing consumers to choose carbon efficient means of travel. A medium intensity investment in public transport is assumed (T2025 Scenario 4, Full Programme) and a medium level of fare reduction. The scenario therefore includes Crossrail (the major west-east cross London public transport scheme).

- PP5 Walking and Cycling: similarly, investment in walking and cycling facilities and in the streetscape and public realm makes carbon efficient means of travel more attractive, particularly for short journeys. A very high intensity investment in walking and cycling is included (much beyond the current level of planned investment in even T2025 Scenario 4, Full Programme). Walking km increase by $158 \%$ (on a high base) and cycling by a factor of nearly 10 (on a low base), both relative to 2006 . 
- PP6 Urban Planning: this package focuses on using urban structure to support sustainable transport, with efforts directed at both strategic and local scales. Strategically, urban planning is used to support public transport use through higher density development being clustered around an upgraded public transport system. This scenario assumes a medium intensity application of urban planning to reduce travel $\mathrm{CO}_{2}$ emissions (London Plan+) - so a greater effort than the current policy approach in using higher densities and the location of development to support sustainable transport.

- PP7 ICT: the scope for $\mathrm{CO}_{2}$ reduction from this package seems limited. A complex adaptation of social interaction is more likely than a simple substitution. A low intensity application of ICT is assumed and the impacts remain minimal in terms of transport $\mathrm{CO}_{2}$ reduction.

- PP8 Smarter Choices Behavioural Measures: this scenario assumes a medium intensity application of smarter choice measures (Cairns et al., 2004) to reduce travel $\mathrm{CO}_{2}$ emissions, reflecting that more intensive efforts may prove less successful when applied to less receptive populations. There have however been very positive results from the Sustainable Travel Towns in the UK, so there may be much more potential here (DfT, 2009; Sloman et al., 2010).

- PP9 Slower Speeds and Ecological Driving: a medium intensity application of this package is included - a $30 \mathrm{~km} / \mathrm{hr}(20 \mathrm{mph})$ speed limit on residential roads and $80 \mathrm{~km} / \mathrm{hr}(50 \mathrm{mph})$ on the strategic road network. This would progress the current policy approach in this area in London. Effective speed limit enforcement is also assumed.

- PP10 Long Distance Travel Substitution: a low intensity application of this package is included. Only travel within the Greater London boundary is modelled hence the $\mathrm{CO}_{2}$ reduction impacts remain small.

- PP11 Freight Transport: a low intensity application of the package and $\mathrm{CO}_{2}$ reduction impacts remain small.

The exact specification of optimal pathways can of course be altered and modified over time to avoid path dependence and 'lock in' to directions that lead to noneffective outcomes. Smarter choices, for example, may benefit from a higher level of application if a wider range of social groups can be persuaded of the need to move towards sustainability in travel lifestyles.

\section{DELHI}

\subsection{Context and Baseline}

The context for Delhi is, of course, very different, but the common aspiration is to develop in a sustainable manner. From the 1980s to the present day, Delhi (and the rest of India) has experienced a rapid rise in cross-sectoral and transport $\mathrm{CO}_{2}$ emissions, but from a very low base in per capita terms. India is currently the world's fourth largest fossil fuel $\mathrm{CO}_{2}$ emitting country in aggregate emissions.

The population of Delhi is currently at 14.8 million, with a projected growth of over $75 \%$ to 26 million by 2030 - nearly three times the projected size of London in 
2030. GDP is expected to grow at up to $8 \%$ per annum (TERI, 2006). GHG, $\mathrm{CO}_{2}$ emission and general travel data is difficult to source in Delhi. The baseline position and future projections discussed below are all based on limited data availability. The estimates are that the transport sector produces around $10 \%$ of total $\mathrm{CO}_{2}$ emissions. Road transport contributes to $95 \%$ of this. Passenger road transport $\mathrm{CO}_{2}$ emissions in Delhi are expected to rise from around $6 \mathrm{MtCO}_{2}$ (2004) to over 26 $\mathrm{MtCO}_{2}$ (2030) under a BAU projection. This equates to 0.4 tonnes $\mathrm{CO}_{2}$ per person (2004) rising to 1.0 tonnes $\mathrm{CO}_{2}$ per person (2030). Much of this is driven by rapid projected mobility growth, including rises in vehicle ownership and use (Hickman et al., 2008, Saxena, 2010). Current transport policies in Asia lead to major threats to quality of life (Tiwari, 2003), and in response the Government of India (2007) has prepared a White Paper on pollution in Delhi. This has led to the establishment of the Environmental Pollution Control Authority with responsibility for reducing vehicular pollution. Much of the early work in Delhi was concentrated on local air quality issues rather than $\mathrm{CO}_{2}$ emissions, but 'strategic' emission issues have certainly attracted more attention in recent years.

No governmental targets have been adopted for reducing projected transport $\mathrm{CO}_{2}$ emissions in India or Delhi. Under the Kyoto Protocol, India's commitments do not involve a numerical $\mathrm{CO}_{2}$ growth limitation, simply an agreement to monitor emissions. The UN agreed to a set of a 'common but differentiated responsibilities', in that:

- The largest share of historical and current global emissions of greenhouse gases has originated in developed countries;

- Per capita emissions in developing countries are still relatively low;

- The share of global emissions originating in developing countries will grow to meet their social and development needs.

Hence India, and other developing countries including China, share only a 'monitoring' responsibility, alongside a more general agreed 'common responsibility' that all countries have a role to play in reducing emissions. The Copenhagen Accord Pledge (January 2010) for India is to reduce their energy intensity (the amount of carbon emissions for each unit of economic output, measured in Gross Domestic Product) by 20-25 percent by 2020. This means that $\mathrm{CO}_{2}$ emissions can still increase, but at a lower rate than GDP.

\subsection{Scenario Testing}

Despite the BAU projections and India's limited 'legal' requirements, much can be done to reduce transport $\mathrm{CO}_{2}$ emissions in Delhi. The transport scenario analysis presented here draws mainly on the VIBAT India and Delhi scoping study ${ }^{6}$, but also subsequent discussions with IIT Delhi ${ }^{7}$ and work from Wilbur Smith Associates (2008). The former study examined the potential application of backcasting

\footnotetext{
${ }^{6}$ Hickman et al. (2008) VIBAT India and Delhi Scoping Study. Halcrow and University of Oxford, Transport Studies Unit for the Asian Development Bank. Again a spreadsheet model is developed for the city, representing passenger travel movements and potential $\mathrm{CO}_{2}$ mitigation by policy area. The data however is much more uncertain in Delhi than in London.

${ }^{7}$ With Professor Dinesh Mohan and Dr Geetam Tiwari, Indian Institute of Technology, Delhi.
} 
methodologies to India and Delhi and developed a number of working scenarios for the transport sector. There are a large potential number of trajectories for Delhi to follow in terms of future transport strategy. The modelling examines combinations of policy interventions grouped into policy packages. The forecast year is again 2030. The packages considered in the Delhi work are different to those in London, including coverage and potential level of application, reflecting the very different context. They include:

- PP1: Low Emission Vehicles

- PP2: Alternative Fuels

- PP3: Vehicle Class Market Share (car/SUV/2-wheeler/3-wheeler)

- PP4: Public Transport

- PP5: Walking and Cycling

- PP6: Urban Planning

- PP7: Wider 'Behavioural' Interventions (combined pricing regimes, traffic demand management (TDM), ecological driving and slower speeds, information and communication technologies (ICT), long distance travel substitution)

- PP8: Freight Transport

A description of Scenarios 1-3 is given below, together with key transport outputs in Figure 4 (aggregate transport $\mathrm{CO}_{2}$ emissions), Figure 5 (mode share by distance) and Figure 6 (per capita transport $\mathrm{CO}_{2}$ emissions).

- Baseline (1990 - 2004)

- BAU Scenario (2030): this future is an extension of existing trends over the next 20 years - some investment in public transport, limited change in the efficiency of the car stock and in the use of alternative fuels. Large projected growth in traffic, with an approximate $700 \%$ increase in $\mathrm{CO}_{2}$ emissions on 1990 levels.

- Scenario 1 - Lower Carbon Driving (2030): a strong and successful push on technological innovation, including low emission vehicles, alternative fuels and smaller vehicle types, with an approximate 500\% increase in $\mathrm{CO}_{2}$ emissions on 1990 levels.

- Scenario 2 - More Active Travel (2030): less optimistic about the potential implementation of low carbon vehicles and relies more on public transport, walking and cycling investment and behavioural measures, with an approximate $300 \%$ increase in $\mathrm{CO}_{2}$ emissions on 1990 levels.

- Scenario 3 - Sustainable Transport (2030): this scenario combines the best technological and behavioural application of scenarios 1 and 2 to deliver an approximate $200 \%$ increase in transport $\mathrm{CO}_{2}$ emissions, on 1990 levels. It is very optimistic about levels of application of policy levers. 


\section{FIGURE 5}

\section{FIGURE 6}

\subsection{Optimal Pathways: Scenario 3 - Sustainable Transport}

The most effective scenario (Scenario 3) is described in more detail below. This pushes extremely hard on all of the available policy levers and implements the technological and behavioural options to a high intensity level. It hence pulls together the application of PP1-PP3 from Scenario 2 and the application of PP4-PP8 from Scenario 3. High levels of low emission vehicle take up, a small size car fleet, and high investment in public transport, walking and cycling, and a supportive urban structure, are all envisaged. The scenario, when modelled, achieves a $68 \%$ reduction in transport $\mathrm{CO}_{2}$ emissions on BAU levels and a $167 \%$ increase on 1990 levels.

Again, an important feature can be seen in Figure 5 - car distance and vehicle $\mathrm{gCO}_{2} / \mathrm{km}$ are the most important features to resultant emissions. In Scenario 3 (and 2) overall travel distance increases markedly on current levels, but car distance remains similar to 2010 projections, with the difference taken up by a very large increase in bus (potentially a wider bus rapid transit network, but also more extensive use of a clean bus fleet), rail (an extended metro system) and cycling. Two and three-wheeler also have much potential, if cleanly fuelled (three wheelers are currently fuelled with compressed natural gas). Figure 6 shows that per capita emissions reduce to below the aspirational 0.5 tonnes per capita under Scenario 3 (note again this is just passenger road travel).

- PP1 Low Emission Vehicles: these achieve reduced fuel consumption and emissions through innovative engine design, including hybrid petrol vehicles, diesel and electric engines. In the Delhi context, this technology is still novel and expensive, but globally hybrid cars are available. The scenario assumes much of the vehicle fleet is based on current best hybrid technology, with a total car/LGV fleet average of around $100 \mathrm{gCO}_{2} / \mathrm{km}$. This is a very ambitious level of technology penetration based on current patterns of take up in India; the current focus is on inexpensive, 'older' technology small car options. There are plans for hybrids to be made available in India, including the Honda hybrid Civic Sedan, Mahindra Industries hybrid SUV, and TVS and Bajaj Auto are developing a hybrid three wheeler. Import taxes mean that non-Indian produced vehicles are prohibitively expensive (there is a current $100 \%$ import duty for vehicles, with some discount for hybrids). Improved fuel economy standards would be required, the motor vehicles (four wheel or more) sold in India are not particularly fuel efficient by international standards. Currently there are no voluntary or mandatory standards in India and manufacturers are only required to publish fuel economy figures, but there are no agreed test cycles (Government of India, Auto Fuel Policy, 2003).

- PP2 Alternative Fuels: there are many possible alternative fuels on the market, many of which have lower carbon content than petrol and diesel, and including biofuels. Ethanol and biodiesel are potentially most suited to use in India. This scenario assumes a rising blend of biofuels in petrol and 
diesel, reaching $30 \%$ by 2030 and a significant proportion of electric and compressed natural gas vehicles. The Government of India has already introduced a programme of 5\% ethanol in petrol (2003). There may be difficulties in implementing this level of biofuel use in terms of land take and infrastructure requirements, and there are ongoing concerns over lifecycle costs. Second and third generation biofuels may provide more opportunities in future years. Jatropha, for example, has potential for biodiesel production in India.

- PP3 Vehicle Class Market Share (car/SUV/2-wheeler/3-wheeler): the scenario assumes reduced growth in the car and particularly SUV market against BAU levels. Instead, the following proportions are assumed in terms of distance travelled market share by 2030 - car (12\%), SUV $(0.5 \%)$, bus (33\%), rail (34\%), walk (6\%), cycle (7\%), 2-wheeler (3\%).

- PP4 Public Transport: the current ring rail network in Delhi is vastly underutilised, with the railways catering for only $1 \%$ of local traffic. The new Delhi Metro is still limited in terms of network coverage and directly benefits only 3-4\% of the city's population (Mohan, 2006), though does serve 0.5 million riders per day. $186 \mathrm{~km}$ of Metro are planned by 2010 . A bus rapid transit (BRT) system has also been developed in Delhi (2008). Under this scenario, there are significant shifts to public transport, including major investment in a more extensive Metro network and bus rapid transit system to 2030. Critically, the development of major transport corridors and interchanges is closely coordinated with urban planning to encourage greater ridership potential (see PP6). This integrated urban structure and transport planning is not occurring to any great extent in current plans.

- PP5 Walking and Cycling: there is major investment in walking and cycling facilities. These modes are critical to the mobility of the majority of Delhi's population. More than $50 \%$ of the population cannot afford any other means of travel unless heavily subsidised (Mohan, 2006).

- PP6 Urban Planning: strategic and local masterplanning is used to 'retrofit' the Delhi urban structure to more closely integrate with the planned public transport investments. Major efforts are made in terms of public transport orientated development and polycentric concentration at key interchanges, including developing a more intensive central business district and local centres. The city is of such a size (a projected 26 million population by 2030) that polycentric concentration, served by Metro, BRT, walking and cycling, and low emission vehicles, becomes a critically important policy intervention.

- PP7: Wider Behavioural Interventions: are also developed, potentially including pricing regimes (perhaps greater fuel taxes, with hypothecated funds for public transport, walking and cycling facilities); traffic demand management (TDM), including restricted parking (where applicable), road space reallocation and wider initiatives such as ecological driving and slower speeds and potentially even travel planning. ICT is also widely used, including high levels of broadband access, to encourage flexible working, home retailing, and electronic social interaction. 
- PP8 Freight Transport: this package concentrates on the freight sector as a whole with a series of measures targeted at reducing $\mathrm{CO}_{2}$ emissions. Measures are introduced to change handling factors (the number of links in the supply chain), reduced length of haul, improved rail mode share, reduced empty running, improved fuel efficiency and choice of fuel/power source.

\section{DISCUSSION AND CONCLUSIONS}

This paper develops a number of potential scenarios for the transport sector for very different contexts in London and Delhi. It is based on scenario analysis and modelling for both cities. All future scenarios that lead to any level of transport $\mathrm{CO}_{2}$ emission reduction imply large trend-breaks relative to the BAU. In both cities, the use of a wide range of policy packages is important in moving decision making in transport planning away from carbon inefficiency and a strategy which is often made up of individual, uncoordinated and poorly integrated projects.

Figure 7 (per capita transport $\mathrm{CO}_{2}$ emissions by scenario and case study) draws together the previous scenario work and suggests transport futures, which are potentially attainable, and would lead to broadly equitable per capita transport emissions, around the aspirational 0.5 tonnes per capita. Again we should note that international air and shipping emissions are not included in this analysis, and Delhi considers only passenger movements. A trading mechanism may help with flexibility in implementation (possibly delivered at the national level), but of course the 'flexibility' here tends to be for the richer countries in allowing greater emissions. Under the strong assumptions in Scenario 3, the per capita transport emissions in London could be lower than those in Delhi, possibly reflecting the more compact urban structure and more dense public transport network. Lower strategic stabilisation targets (below 500 ppm $\mathrm{CO}_{2} \mathrm{e}$ ) would demand even more stringent delivery within the transport sector, below 0.5 tonnes per capita.

\section{FIGURE 7}

The successful implementation of vehicle efficiencies and alternative fuels to the mass market is critical, but this is currently not happening at the levels required. There are clear opportunities in encouraging low emission, small size and low price vehicle technology (particularly in Delhi), and potentially using lean burn technologies. Financial incentives may be required here, including linking vehicle import duty to emissions in the short term. Some technological policy measures appear to be more limited in potential as they undergo closer examination (e.g. biofuels).

The potential $\mathrm{CO}_{2}$ reduction gains from technological change are likely to be offset by the projected rapid growth in traffic. Behavioural change is essential to help 'lock in' any benefits, and should be aimed at reducing the projected growth in travel, particularly car-based travel. Some behavioural change policy areas appear to be very important, but are underplayed in policy terms. These include pricing regimes (perhaps via a carbon tax, fuel duty, or emissions-based charging), smarter choice measures, and urban form and layout to promote short distance trips, which in turn may increase the use of public transport, cycling and walk. These packages 
are particularly important in both cities, as achieving ambitious targets mean that a much greater share of trips need to be made by non-car modes. The potential for effective policy packaging, with the objective of developing synergies, is poorly understood and would benefit from further research.

The concept of effective participation will be important if significant behavioural change is to be developed. This involves generating effective strategies and also the 'ownership' of different travel behaviours through improved participation in the debate and awareness. The scenarios as developed, or similar, can be used as 'storylines' for discussion, helping sort through the priorities for intervention and investment, and to further understand the likely trade-offs in decision-making. Key decision makers should be involved early in the process to help them to buy into both the scale of change necessary to achieve the strategic policy ambitions (major reductions in London and moderate increases in Delhi) and the immediacy required in terms of action. Firstly, the conversations need to involve politicians, planners, business and industry, as well as community and environmental groups. In addition, there is a clear need for leadership at the city level and for individuals who are prepared to address the issues of climate change seriously and to be seen as the 'champions' of the new low carbon city. Secondly, there is often a belief that technological solutions are all that is required. The analysis has demonstrated in both cities that this is not well-founded, indeed is based on very outdated logic, as the take up of technology is a slow process, there are possible large rebound effects, as well as a continuing increase in demand for travel with the growth in trips (Delhi) and the distances travelled (London and Delhi). Participatory processes will of course be difficult, particularly in contexts such as Delhi (high illiteracy rates) and London (vocal minorities supporting certain standpoints). There may however be an international dimension to explore in the possibilities of the two cities learning from each other, and in particular for Delhi to introduce 'clean' technologies for public transport without having to pass through the 'car experience'.

There may be some synergies that could be promoted between even these two very different cities. London is an innovator in terms of sustainable transport, with the experience of nearly 140 years' investment in a modern public transport network (the first Underground Line was built in 1863), including different modes of public transport; a compact polycentric urban form, with a dominant and high density, mixed-use central area, and attractive areas for urban living; a land use planning system that has helped focus growth in particular areas, including in east London, around the key public transport interchanges, and beyond London in the New Towns; car free and low car residential developments; a congestion charging scheme; car sharing schemes and clubs; some innovative streetscape designs; and a recent cycle hire scheme. Conversely, in Delhi, the current low emission vehicle types (two and three wheelers) offer much in terms of flexibility and demand responsiveness, often with high occupancies. They perhaps have resonance in other low density suburban areas. The Delhi vehicle stock tends to be small in size and light in weight. There are existing high levels of walking and cycling, and many short trip distances relative to those found in London. The transfer of knowledge between leading cities can be much strengthened in what will need to be a global effort towards sustainable mobility. 
The analysis here has looked at the city 'in isolation' and not in terms of its linkages with the rest of the World through travel (aviation), trade (shipping), and ecommunications. The shorter distance travel within cities makes it easier to creatively look at a range of different options, and in combination, and it is possible under different scenarios to achieve substantial reductions in carbon emissions. When the wider picture is examined there are fewer options in terms of both the technologies available and in the alternative means by which business and leisure trips can be undertaken. The globalisation of the economy and the long supply chains needed to provide food, energy, goods and materials for cities have not been considered here. These important international carbon emissions sources are outside of the international agreements at present, and it is difficult to see how they will be included in terms of the measurement of their scale, allocations, the monitoring of target achievement and the individual responsibilities for action. As with the interventions needed within our two case cities, there are many responsible agents and actions need to be taken at all levels (international, national, city and individual), and effectively combined, to ensure progress is made. Movement towards ambitious targets is very likely to be slow, and more understanding is required on the social and cultural dimensions behind travel behaviours (Urry, 2007), and the propensity for change. All these very important issues are beyond the scope of this paper.

Further research might include a more thorough review of potential policy mechanisms, likely impacts and priorities at the local level. Data in contexts such as Delhi is particularly scarce. Sensitivities and assumptions are also very important in scenario testing, particularly over the long term, as a minor change to assumptions can make very large differences to end results. A more detailed examination would consider different levels of application for different policy packages, sensitivities by key variables (fuel efficiency, occupancy, distance travelled, oil price changes) and also issues such as policy package synergies (positive and negative), rebound effects and lock in potential. The current modelling tools struggle to handle many of these effects in a robust manner. Cost-benefit analysis and wider multi-criteria appraisal also need much more exploration in terms of considering the wider impacts of low carbon pathways.

Strategic conversations, using techniques such as scenario testing, may become central in allowing decision makers, wider stakeholders and the public to participate in critical discussions concerning future lifestyles. Leadership by governmental organisations and civil society and public ownership of the chosen policy pathways is critical. The BAU projections for transport in Delhi and elsewhere in Asia are extremely challenging, even though it is generally accepted that trend-based futures are unsustainable. However, even in countries that are experiencing severe pressures for very substantive increases in travel demand, it is possible to explore the means by which low energy and carbon futures can be addressed. Workable models of low carbon transport lifestyles need to be demonstrated in a clear and attractive manner. These need to be perceived as positive future lifestyle choices to help overcome the future discounting problem. The advantage that Asia has is that most consumers are not used to carbon intensive lifestyles. The 'leapfrog' transition to a low carbon future is possible, and the Asian experience can provide an example for wider cities. The challenge is clear, but the constraints of time and the scale of the changes 
required, demand an urgent, participative and transparent discussion of the potential pathways ahead. 0.5 tonnes $\mathrm{CO}_{2}$ per capita can be the broad strategic aspiration for the transport sector, within which contextual variety and implementation options are discussed. Action in the short term (with sufficient ambition) is the key to achieving radical change in the longer term.

Acknowledgements: many thanks to the UrbanBuzz programme (www.urbanbuzz.org) for funding the VIBAT London study (UCL, UeL, HEFCE and DIUS, 2007-09) and the Asian Development Bank for funding the VIBAT India and Delhi scoping study (ADB, 2008). These studies provide the basis for much of the data used in this paper. Also wider team members who have helped develop the work in the VIBAT series of studies (www.vibat.org) - from Halcrow and University of Oxford, Transport Studies Unit. Thanks also to two anonymous reviewers who provided useful and constructive comments on improving the paper. The views expressed in this paper are of course from the authors and do not necessarily reflect those of the project funders or other contributors.

\section{References}

Åkerman, J. and Höjer, M. (2006) How much transport can the climate stand? Sweden on a sustainable path in 2050. Energy Policy, 34: 1944-1957.

Anable, J. and Bristow, A.L. (2007) Transport and Climate Change. Supporting document to CfIT report on Transport and Climate Change. London: Commission for Integrated Transport.

Ashiru, O., Hickman, R. and Banister, D. (2009) Visioning and backcasting for transport in London (VIBAT London). TC-SIM modelling specification and assumptions. Working Note. London: Halcrow and Oxford University for the UrbanBuzz Programme (available on request from the authors).

Banister, D., Stead, D., Steen, P. Åkerman, J., Dreborg, K., Nijkamp, P. and Schleicher-Tappeser, R. (2000) European Transport Policy and Sustainable Mobility. London: Spon.

Banister, D. (2005) Unsustainable Transport: City Transport in the New Century. London: Routledge.

Banister, D. (2008) The sustainable mobility paradigm. Transport Policy, 15(2): 73-80.

Bows, A. and Anderson, K. L. (2007) Policy clash: Can projected aviation growth be reconciled with the UK Government's 60\% carbon reduction policy? Transport Policy, 14(2): 103-110.

Brand, C., Tran, M. and Anable, J. (2010) The UK transport carbon model: An integrated life cycle approach to explore low carbon futures. Energy Policy, in press.

Bristow, A.L., Tight, M.R., Pridmore, A. and May, A.D. (2008) Developing pathways to low carbon land-based passenger transport in Great Britain by 2050. Energy Policy, 36: 3427-3435

Cairns, S., Sloman, L., Newson, C., Anable, J., Kirkbride, A. and Goodwin, P. (2004) Smarter choices: Changing the way we travel. London: Department for Transport.

Chapman, L. (2007) Transport and climate change: A review. Journal of Transport Geography, 15: 354-267.

Dreborg, K. H. (1996) Essence of backcasting. Futures, 28: 813-828.

Department for Transport (DfT) (2009) Low Carbon Transport: A Greener Future. London: The Stationery Office. 
Frommelt, O. (2008) Strategy, Scenarios and Strategic Conversation: An Exploratory Study in the European Truck Industry. PhD Thesis, Nottingham University.

Geurs, K. and Van Wee, B. (2004) Backcasting as a tool for sustainable transport policy making: The Environmentally Sustainable Transport study in the Netherlands. European Journal of Transport Infrastructure Research, 4: 47-69.

Giddens, A. (2009) The Politics of Climate Change. Cambridge: Polity Press.

Gilbert, R. and Perl, A. (2010) Transport Revolutions: Moving People and Freight without Oil. London: Earthscan.

Greater London Authority (GLA) (2009) The London Plan. London: GLA.

Greater London Authority (GLA) (2007) Action Today to Protect Tomorrow: The Mayor's Climate Change Action Plan. London: GLA.

Godot, M. (2000) The art of scenarios and strategic planning. Technological Forecasting and Social Change, 65(1): 3-22.

Gwilliam, K. (2002) Cities on the Move. A World Bank Urban Transport Strategy Review. Washington, D.C.: World Bank.

Hickman, R., Ashiru, O. and Banister, D. (2010) Transport and climate change: Simulating the options for carbon reduction in London. Transport Policy, 17(2): 110-125

Hickman, R., Ashiru, O. and Banister, D. (2009) Carbon efficiency in transport. Backcasting from London. Transportation Research Record, 2139: 172-182.

Hickman, R. and Banister, D. (2007) Looking over the horizon: Transport and reduced $\mathrm{CO} 2$ emissions in the UK by 2030. Transport Policy, 14(5): 377-387.

Hickman, R., Framer, P., Breithaupt, M. and Saxena, S. (2011) Changing Course in Urban Transport: A Picture Book. Manila: Asian Development Bank and GTZ, forthcoming.

Hickman, R., Bradbury, A., Ashiru, O., Saxena, S. and Banister, D. (2009) Visioning and Backcasting for Transport in London (VIBAT-London). Study Reports, Stages 1, 2 and 3 and Executive Summary. London: Halcrow and University of Oxford for the UrbanBuzz Programme. Available on: www.vibat.org

Hickman, R., Saxena, S. and Banister, D. (2008) Breaking the Trend. Visioning and Backcasting for Transport in India and Delhi. London: Halcrow and University of Oxford, Scoping Study for the ADB.

Hughes, P. (1993) Personal Transport and the Greenhouse Effect. London: Earthscan.

Intergovernmental Panel on Climate Change (IPCC) (2007) Fourth Assessment Report on Climate Change. Geneva: IPCC.

Kahn, H. and Wiener, A.J. (1967) The Year 2000: A Framework for Speculation on the Next Thirty Years. New York: Macmillan.

Linnerud, K. and Holden, E. (2011) The troublesome leisure travel: Contradictory results of sustainable policies. Urban Studies, forthcoming.

Lindblom, C.E. (1959) The science of muddling through. Public Administration Review, 19(2): 7988.

Mackay, D.J.C. (2009) Sustainable Energy - Without the Hot Air. Cambridge: UIT. 
Meyer, A. and Global Commons Institute (2000) Contraction and Convergence. The Global Solution to Climate Change. Totnes: Green Books.

Mohan, D. (2006) Squandering public funds for a handful of people. Business Standard. New Delhi.

Newman, P. and Kenworthy, J. R. (1999) Sustainability and Cities: Overcoming Automobile Dependence. Washington, D.C.: Island Press.

Nicholls, R.J., Hanson, S., Herweijer, C., Patmore, N., Hallegatte, S., Corfee-Morlot, J., Chateau, J. and Muir-Wood, R. (2008) Ranking Port Cities with High Exposure and Vulnerability to Climate Extremes, OECD, Environment Working Paper 1, ENV/WKP(2007) republished on 19 November 2008. www.oecd.org/env/workingpapers

Organisation for Economic Co-operation and Development (OECD) (2000) EST! Environmentally Sustainable Transport. Futures, Strategies and Best Practice. Synthesis Report. Paris: OECD.

Pharoah, T. (1992) Less Traffic, Better Towns. London, Friends of the Earth.

Renewable Fuels Agency (RFA) (2008) The Indirect Effects of Biofuels Production [The Gallagher Review]. London: RFA.

Robinson, J.B. (1982) Energy backcasting: A proposed method of policy analysis. Energy Policy, 10(4): 337-344.

Robinson, J.B. (1990) Futures under glass: A recipe for people who hate to predict. Futures, 22(8): 820-842.

Saxena, S. (2010) Low Carbon Transport Pathways in Delhi. DPhil (in development). University of Oxford.

Schäfer, A., Heywood, J.B., Jacoby, H.D. and Waitz, I.A. (2009) Transportation in a Climate Constrained World. Cambridge, MA: MIT Press.

Schipper, L. J. and Fulton, L. (2003) Carbon dioxide emissions from transportation: Trends, driving factors, and forces for change. In: Hensher, D. A. and Button, K.J. (ed.) Handbook of Transport and the Environment. London: Elsevier.

Schwartz, P. (1996) The Art of the Long View: Paths to Strategic Insight for Yourself and Your Company. New York: Doubleday.

Sloman, L., Cairns, S., Newson, C., Anable, J., Pridmore, A. and Goodwin, P. (2010) The Effects of Smarter Choice Programmes in the Sustainable Travel Towns: Summary Report. London: DfT.

Sperling, D. and Gordon, D. (2009) Two Billion Cars. Driving Towards Sustainability. Oxford University Press.

Stern, N. (2009) A Blueprint for a Safer Planet. London: Random House.

The Energy and Resource Institute (TERI) (2006) National Energy Map for India. New Delhi: TERI for Government of India.

Thompson, J. M. (1977) Great Cities and Their Traffic. London: Gollancz

Transport for London (TfL) (2006) Transport 2025: Transport Vision for a Growing World City. London: TfL/GLA.

Transport for London (TfL) (2009) The Mayor's Transport Strategy. London: TfL/GLA.

Tiwari, G. (2003) Transport and Land-use Policies in Delhi. Bulletin of the World Health Organisation, 81(6). 
Urry, J. (2007) Mobilities. Cambridge: Polity.

Van der Heijden, K. (1996) Scenarios: The Art of Strategic Conversation. Chichester: Wiley $\left(2^{\text {nd }}\right.$ Edition).

Wilbur Smith Associates (2008) Traffic and Transportation Policies and Strategies in Urban Areas in India. Ministry of Urban Development.

World Bank (2010) Millennium Development Indicators. Washington DC: World Bank.

Yang, C., McCollum, D., McCarthy, R. and Leighty, W. (2009) Meeting an 80\% reduction in greenhouse gas emissions from transportation by 2050: A case study in California. Transportation Research D, 14(3): 147-156. 


\section{FIGURES}

Figure 1: Aggregate Transport CO2 Emissions (London)

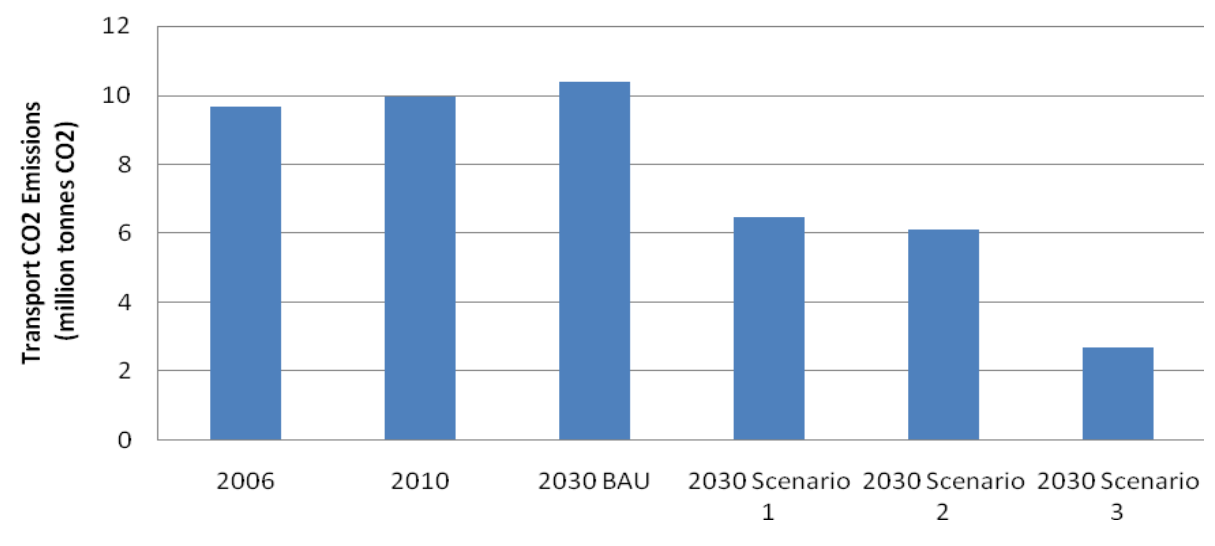

Note: projections, targets and target achievement are given in this analysis to 2030. This is earlier than the Stern (2009) and international/national agreement end dates which tend to be to 2050. This reflects work done in previous studies by the authors on London and Delhi, and also the possible need to be more 'progressive' relative to the 'conservative' stance of Stern and the omitted issues such as international aviation and different stabilisation levels. Budgetary analysis (the area under the line) is also important, encouraging action to be taken quickly.

Figure 2: Mode Share (Passenger kms) (London)

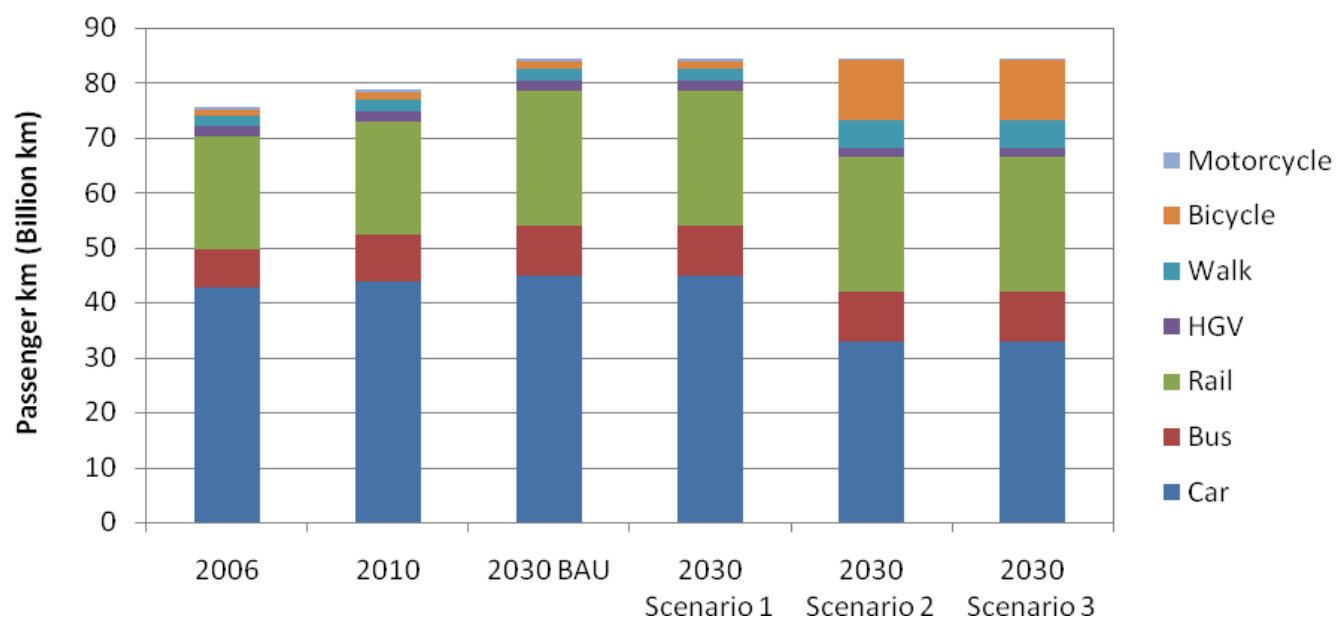


Figure 3: Per Capita Transport CO2 Emissions (London)

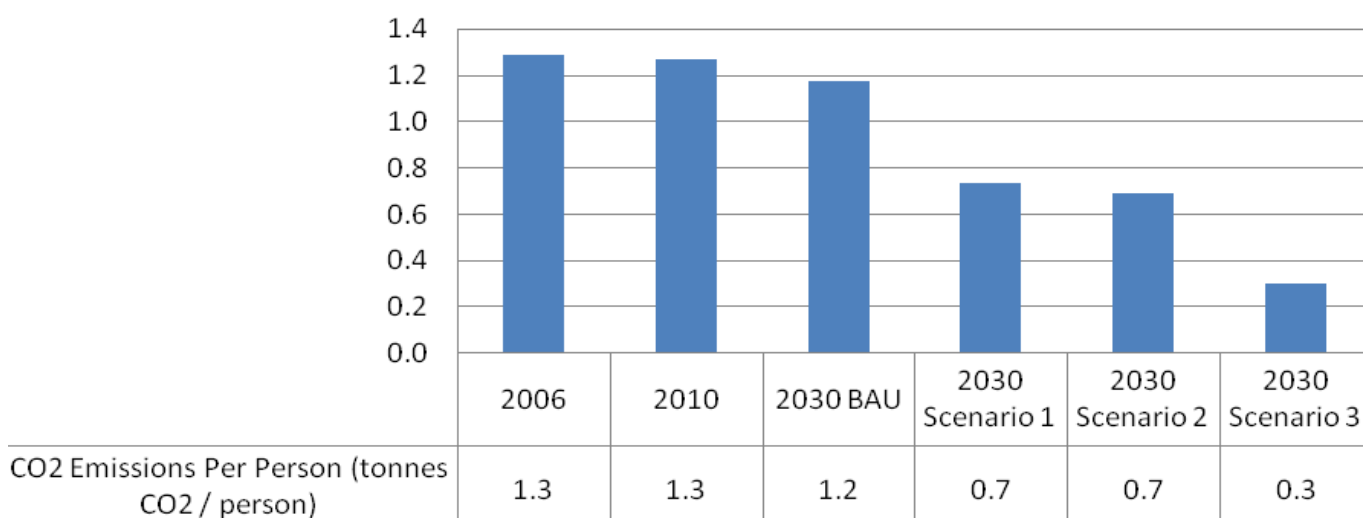

Figure 4: Aggregate Transport CO2 Emissions (Delhi)

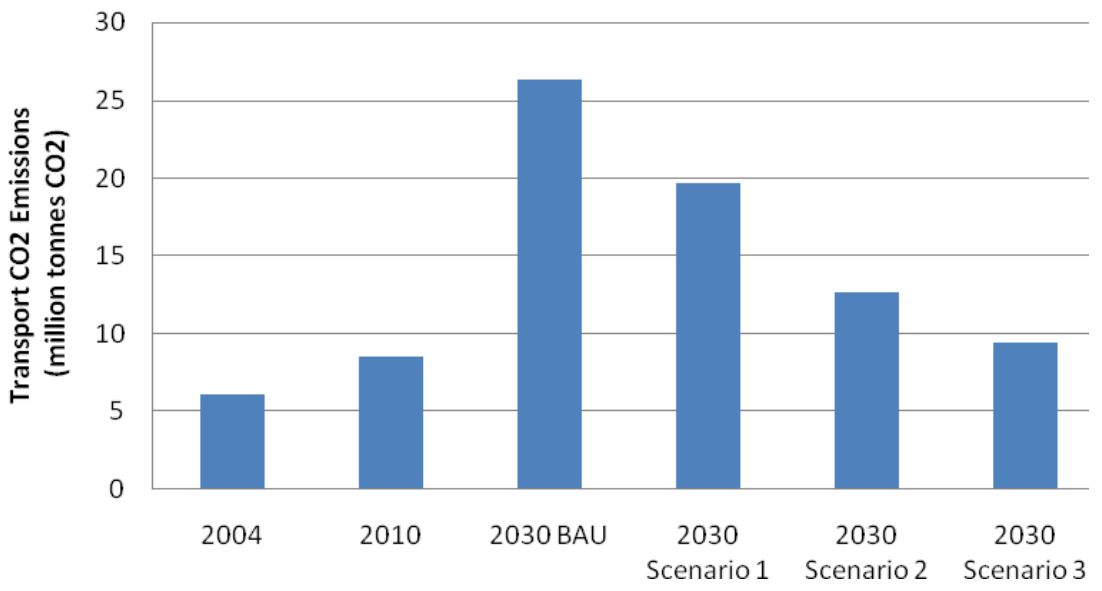

Figure 5: Mode Share (Passenger kms) (Delhi)

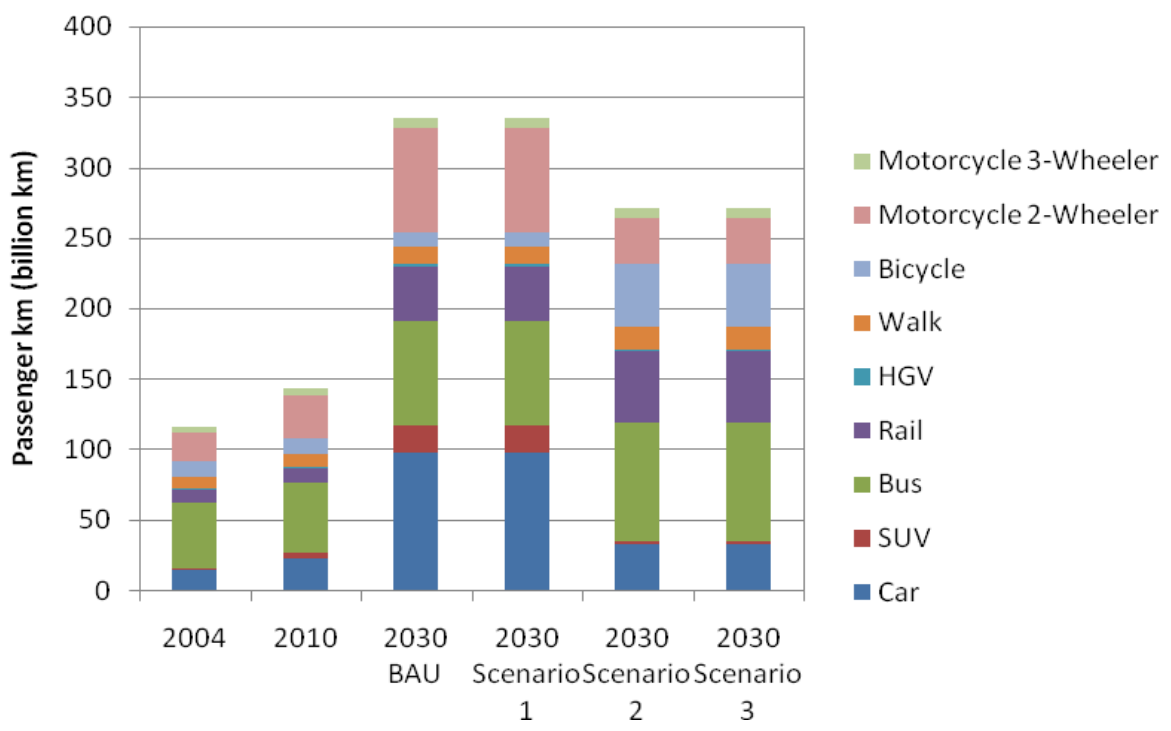


Figure 6: Per Capita Transport CO2 Emissions (Delhi)

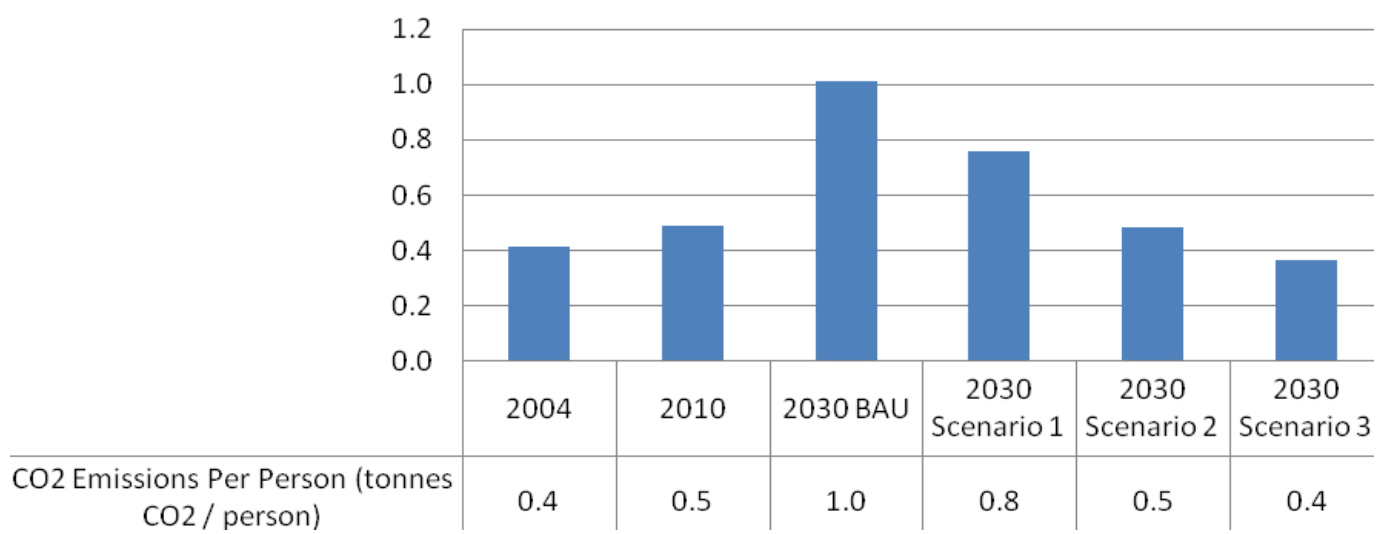

Figure 7: Summary Scenarios - London and Delhi

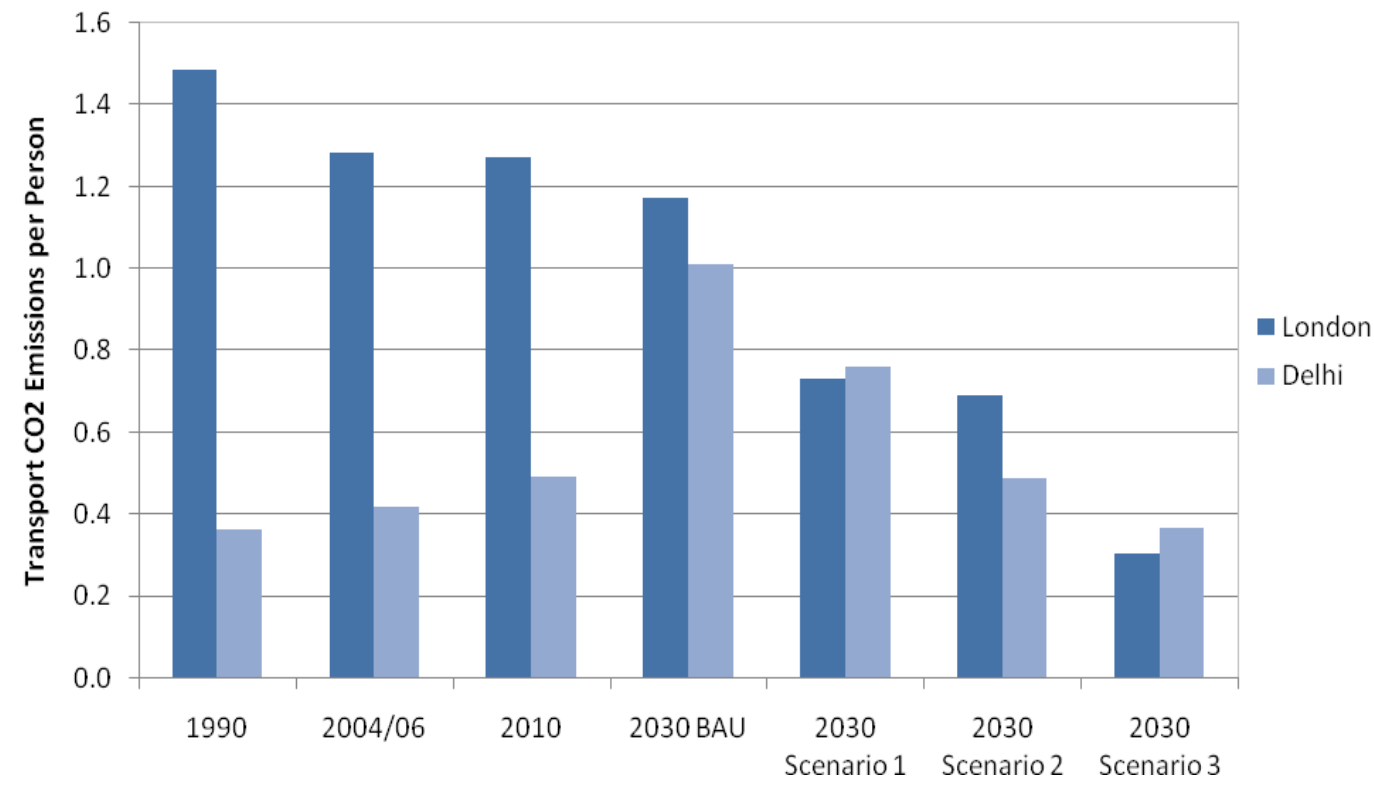


Table 1: Per Capita Cross Sectoral CO2 Emissions

\begin{tabular}{|l|l|l|}
\hline Country & $\mathbf{1 9 9 0}$ & $\mathbf{2 0 0 5}$ \\
\hline United Kingdom & 9.9 & 9.0 \\
\hline India & 0.8 & 1.3 \\
\hline United States & 19.2 & 19.5 \\
\hline World & 4.3 & 4.5 \\
\hline
\end{tabular}

Note: Metric tons per capita

World Bank, 2010 - Millennium Development Indicators

Table 2: CO2 Concentration Levels and Temperature Increases

\begin{tabular}{|l|c|c|c|c|c|c|}
\hline \multirow{2}{*}{$\begin{array}{l}\text { Stabilisation } \\
\text { Level (ppm } \\
\mathbf{C O}\end{array}$} & \multicolumn{6}{|c|}{ Likelihood of Exceeding } \\
\cline { 2 - 7 } & $\mathbf{2}^{\mathbf{}} \mathbf{C}$ & $\mathbf{3}^{\mathbf{0}} \mathbf{C}$ & $\mathbf{4}^{\mathbf{0}} \mathbf{C}$ & $\mathbf{5}^{\mathbf{}} \mathbf{C}$ & $\mathbf{6}^{\mathbf{}} \mathbf{C}$ & $\mathbf{7}^{\mathbf{0}} \mathbf{C}$ \\
\hline 450 & 78 & 18 & 3 & 1 & 0 & 0 \\
\hline 500 & 96 & 44 & 11 & 3 & 1 & 0 \\
\hline 550 & 99 & 69 & 24 & 7 & 2 & 1 \\
\hline 650 & 100 & 94 & 58 & 24 & 9 & 4 \\
\hline 750 & 100 & 99 & 82 & 47 & 22 & 9 \\
\hline
\end{tabular}

Note: Given the uncertainties, climate sensitivity is described in terms of probabilities against a range of stabilisation levels and temperature increases at equilibrium relative to 1850 - representing average global temperatures across the surface of the planet - ocean and land. Within this there will be much variation by area (Stern, 2009). 


\section{TRANSITIONS TO LOW CARBON TRANSPORT FUTURES. STRATEGIC CONVERSATIONS FROM LONDON AND DELHI}

\section{Dr Robin Hickman,}

Research Fellow

Transport Studies Unit,

Oxford University Centre for the Environment,

University of Oxford, South Parks Road, Oxford, UK, OX1 3QY

robin.hickman@ouce.ox.ac.uk

Associate Director, Transport Research

Halcrow Group Ltd

\section{Olu Ashiru}

Takedo International and Halcrow Group Ltd

Research Student, Centre for Transport Studies, Imperial College London ashiruo@halcrow.com

\section{Professor David Banister}

Transport Studies Unit,

Oxford University Centre for the Environment, University of Oxford, South Parks Road, 